\title{
Infrared Absorption Spectrum of Carbon Disulfide
}

\author{
By Earle K. Plyler and Curtis J. Humphreys
}

\begin{abstract}
The infrared absorption spectrum of carbon disulfide has been remeasured in the region from 2 to $24 \mu$ with cells up to $5 \mathrm{~mm}$ in thickness. Fifteen bands were observed, some however being of low intensity. The strongest band for the liquid occurs at $6.62 \mu$, and the second harmonic of this band was observed at $2.22 \mu$, but the first harmonic, which should be at about $3.33 \mu$, was not observed, in accordance with the selection rules for a symmetrical linear molecule. Four combination bands were observed between 3 and $5 \mu$, whose wavelengths were in good agreement with the calculated values. A combination band, which is represented by the difference between two fundamentals, occurs as a broad, moderately strong band in the region of $11.6 \mu$. A weak band, observed at $15.27 \mu$, corresponds with the wavelength of the inactive vibration of the molecule. However, when this region was studied with a $140 \mathrm{~cm}$ cell filled with the saturated vapor of $\mathrm{CS}_{2}$ at room temperature, no band was observed. In the vapor state a total of six bands were found at waveleingths less than $20 \mu$. The fundamental band at $6.5 \mu$ shows a side branch that is probably due to the isotopic effect produced by $\mathrm{C}^{13}$. Some small bands that were observed may be attributed to the $\mathrm{C}^{12} \mathrm{~S}^{32} \mathrm{~S}^{34}$ molecule. As would be expected for this molecular configuration, the spectrum of $\mathrm{CS}_{2}$ as observed may be classified into an array of terms analogous to those of $\mathrm{CO}_{2}$. A band at $12.7 \mu$ has different intensities for samples obtained from two different sources and may be caused by an impurity. This band did not appear when the cell containing the vapor was used.
\end{abstract}

\section{Introduction}

The infrazed absorption spectrum of carbon disulfide has been measured by many observers $[1,2,3] .{ }^{1} \quad$ The present work has been undertaken primarily to extend the observations to the shortwavelength region, also to compare the spectrum of the liquid with the vapor. In the near-infrared region $\mathrm{CS}_{2}$ is quite transparent, and cell thicknesses of several centimeters may be used with only a small loss in energy. However, because of the presence of strong bands at 4.6 and $6.5 \mu$, and other bands at 3.4 and $3.55 \mu$, very thick cells are almost opaque beyond $3.3 \mu$. Many substances have strong absorption bands in the region between 7 and $15 \mu$. For this region, layers $0.1 \mathrm{~mm}$ in thickness are quite transparent, and carbon disulfide may be used as a solvent in the study of the

${ }^{1}$ Figures in brackets indicate the literature references at the end of this paper.

absorption spectrum of compounds. Carbon tetrachloride, another commonly used substance, is quite absorbing from 12 to $15 \mu$, and is not as satisfactory as $\mathrm{CS}_{2}$ for use as a solvent when absorption measurements are made in this part of the spectrum.

The absorption spectrum of the vapor of $\mathrm{CS}_{2}$ has been measured by Bailey and Cassie [2] and by Dennison and Wright [3], and the molecular structure has been determined to be of the type of $\mathrm{CO}_{2}$. That is, the molecule is linear, and the carbon atom is at the center. Further work by Sanderson [4] on the fine structure of the $4.6 \mu$ band has revealed that the rotational lines are equally spaced, which is further proof that the molecule is linear. Also, Lieberman [5] has resolved a band in the ultraviolet and found that the rotational lines were equally spaced. The Raman spectrum of $\mathrm{CS}_{2}$ has been measured by a number of observers, 
and such data are of great assistance in interpreting the energy levels.

The selection rules for the energy-level transitions in a linear symmetrical molecule are well known. Many of the energy transitions are inactive. In this work on the absorption of the material in the liquid state, a number of bands are found that have not been observed for the gaseous state. This will be discussed after the experimental results are given.

\section{Experimental Results}

A Perkin-Elmer infrared spectrometer was used to measure the absorption spectrum of carbon disulfide. In addition to the rock-salt prism, a LiF prism was used in the region from 3.3 to $3.7 \mu$ and a $\mathrm{KBr}$ prism from 15 to $24 \mu$. A slit-control device, which has been described before [6], was found to simplify the measurements, especially in the long-wavelength region. The experimental arrangements were the same as formerly used, and the description will not be repeated here. Several cell thicknesses were used in various regions of the spectrum. In figure 1 the results for cells $5.0 \mathrm{~mm}$ and $0.10 \mathrm{~mm}$ in thickness have been plotted on the same graph. The 5.0-mm cell showed all the bands that were observed, but in the region of 6.6 and $4.6 \mu$, the bottoms of the bands were broad, and the positions of maximum absorption could not be accurately determined. In table 1 the wavelengths of all the observed bands are given. The values of the observed wavelengths are obtained by taking the average of a number of observations.

Different cell thicknesses were used to display the different bands to best advantage; for example, the band at $2.22 \mu$ absorbs about 15 percent of the radiation with a cell thickness of $5.0 \mathrm{~mm}$, whereas the 4.6- and $6.6-\mu$ bands absorb 100 percent for a cell $0.10 \mathrm{~mm}$ in thickness. The $3.55-\mu$ band showed a slight side band on the long-wavelength side. When this region was investigated with a LiF prism, figure 2 , the two bands were resolved and separated by about $23 \mathrm{~cm}^{-1}$. The band at $6.62 \mu$ is very intense and showed zero transmission from 6.50 to $6.70 \mu$ with a $0.05-\mathrm{mm}$ cell. The

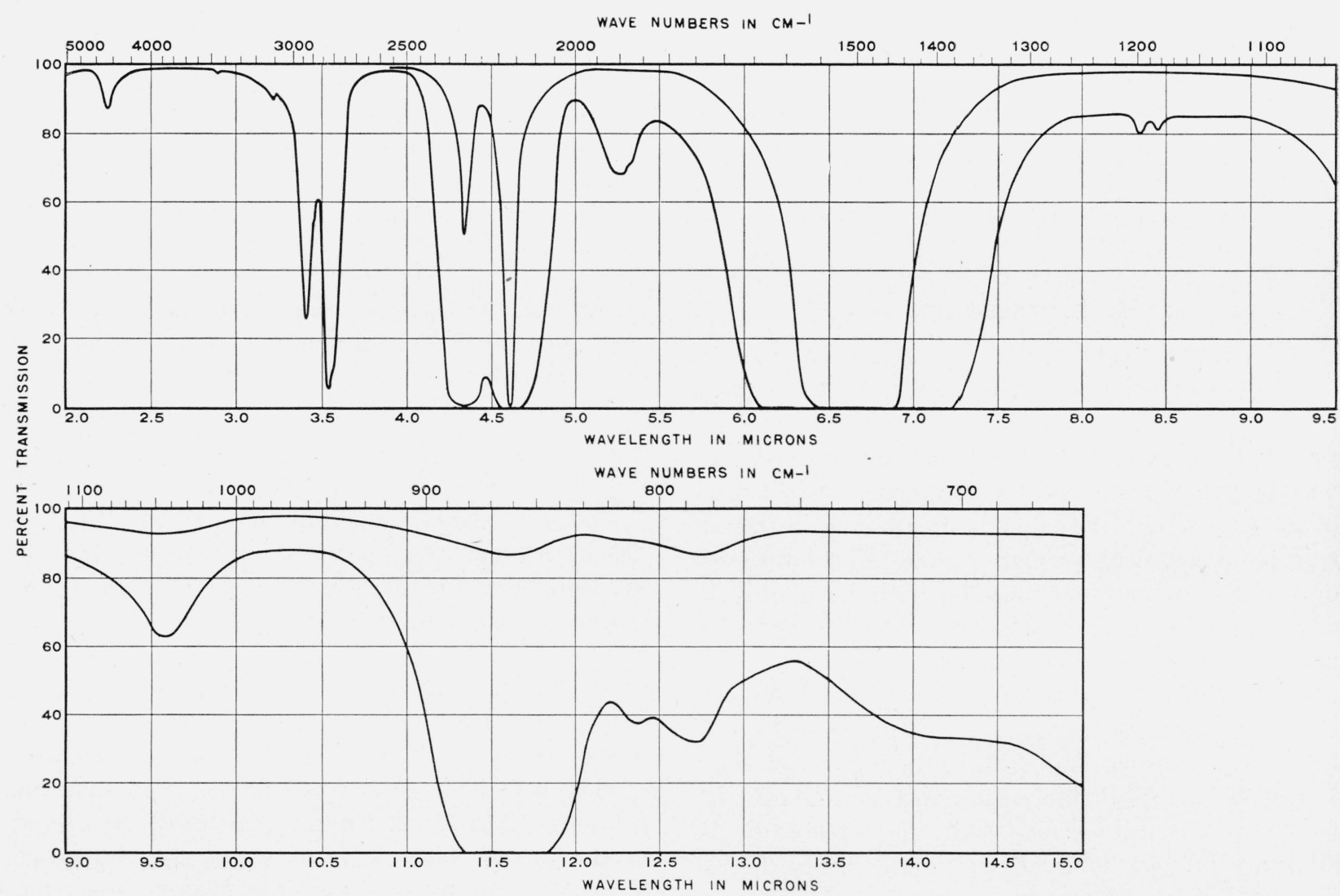

Frgure 1.-Infrared transmission of liquid $\mathrm{CS}_{2}$ for cells of $5 \mathrm{~mm}$ and $0.1 \mathrm{~mm}$ in thickness. 
bands, as observed with a rock-salt prism are fairly sharp and are probably not over $0.02 \mu$ in error. The bands at 11.68 and $12.77 \mu$ are broad, and it is somewhat difficult to determine accurately their maxima of absorption. In the region of $14 \mu$ there is an indication of a band when a $5.0-\mathrm{mm}$ cell is used, but with thinner cells no band was observed. For the thick cells there is considerable general absorption in this region. This is partly due to a band at $15.27 \mu$. This was the only band observed beyond $15 \mu$. There is a small dip at $20 \mu$, but this was not sufficient to be considered as a band, especially as it occurs in a region of general absorption and may be due to experimental error. The percentage transmission is decreasing as the long-wavelength region is reached, and this is caused by the $25-\mu$ band.

TABLE 1.-Observed and calculated bands of carbon disulfide

\begin{tabular}{|c|c|c|c|}
\hline \multirow{2}{*}{ Term } & \multicolumn{2}{|c|}{ Wave number } & \multirow{2}{*}{$\begin{array}{l}\text { Wave- } \\
\text { length } \\
\text { observed }\end{array}$} \\
\hline & Observed & Calculated & \\
\hline & $c m^{-1}$ & $c m^{-1}$ & $\mu$ \\
\hline$\nu_{1--}$ & 655 & 1655 & 15. 27 \\
\hline$\nu_{2} \ldots \ldots$ & 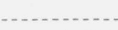 & ${ }^{1} 397$ & ...... \\
\hline$\nu_{3} \ldots \ldots \ldots$ & 1,510 & ${ }^{1} 1,510$ & 6. 64 \\
\hline$\nu_{1}+\nu_{2} \ldots \ldots$ & 1,048 & 1,052 & 9.54 \\
\hline $2 \nu_{2} \ldots$ & 807 & 794 & 12.39 \\
\hline & 783 & & 12. 77 \\
\hline$\nu_{3}-\nu_{1} \ldots$ & 855 & 855 & 11. 66 \\
\hline$\nu_{3}-\nu_{1}=$ & 1,197 & 1,191 & 8.35 \\
\hline $3 \nu_{2} \ldots \ldots$. & 1,180 & - n- & 8.47 \\
\hline$\nu_{2}+\nu_{3} \ldots \ldots \ldots$ & 1,910 & 1,907 & 5. 23 \\
\hline$\nu_{1}+\nu_{3} \ldots \ldots \ldots$ & 2,163 & 2,165 & 4. 62 \\
\hline$\nu_{3}+2 \nu_{2} \ldots \ldots \ldots \ldots$ & 2,303 & 2,304 & 4,34 \\
\hline$\nu_{3}+2 \nu_{1} \ldots$ & 2,815 & 2,820 & 3.55 \\
\hline$\nu_{3}+2 \nu_{1}\left(\mathrm{C}^{12} \mathrm{~S}^{32} \mathrm{~S}^{31}\right)_{\ldots} \ldots$ & 2,793 & 2,796 & 3.58 \\
\hline$\nu_{1}+\nu_{3}+2 \nu_{2} \ldots$ & 2,949 & 2,960 & 3. 39 \\
\hline$\nu_{3}+4 \nu_{2} \ldots$ & 3,105 & 3,098 & 3. 22 \\
\hline$\nu_{3}+3 \nu_{1} \ldots$ & 3,472 & 3,475 & 2. 88 \\
\hline $3 \nu_{3}-\ldots+1$ & 4,504 & 4,530 & 2. 22 \\
\hline
\end{tabular}

1 These values used in calculating other terms.

The transmission for cells of 1.5 and $5.0 \mathrm{~mm}$ in thickness is shown in figure 3 for the long-wavelength region. The $\mathrm{CS}_{2}$ samples used in these measurements were obtained from the firms, J. T. Baker Chemical Co., and Merck \& Co. The Merck product was marked "highly purified." The $\mathrm{CS}_{2}$ obtained from Baker was labeled "Baker's Analyzed," and it was rated very pure. Although the absorption-spectra characteristic of the two samples were essentially identical, an observable difference was apparent. This was especially noteworthy for the band at wave number 783 $\mathrm{cm}^{-1}(12.77 \mu)$. In figure 4 are shown the ob-

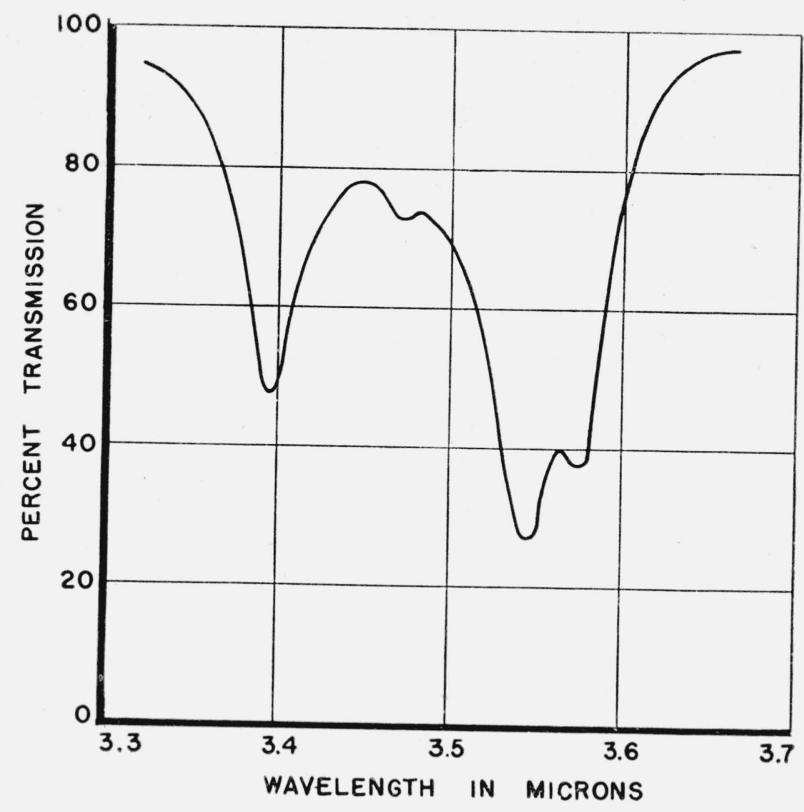

Figure 2.-Spectrum of liquid $\mathrm{CS}_{2}$ in the region of $3.5 \mu$ as measured with a LiF prism (rell thickness about $1.2 \mathrm{~mm}$ ).

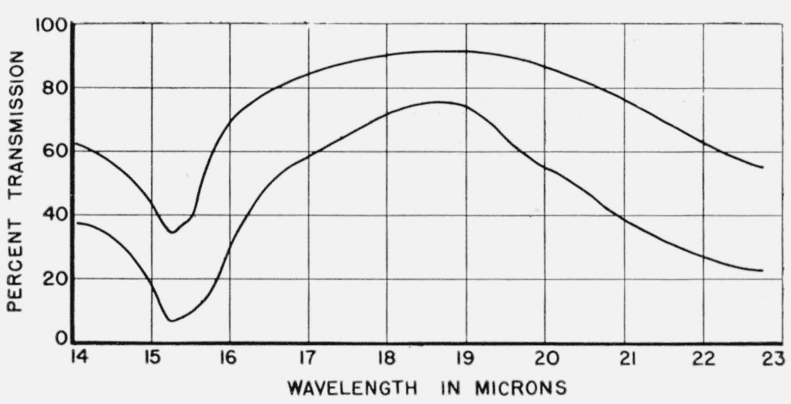

Figure 3.-Transmission of liquid $\mathrm{CS}_{2}$ from 14 to $23 \mu$ as measured with a KBr prism (cells 1.5 and $5.0 \mathrm{~mm}$ in thickness were used).

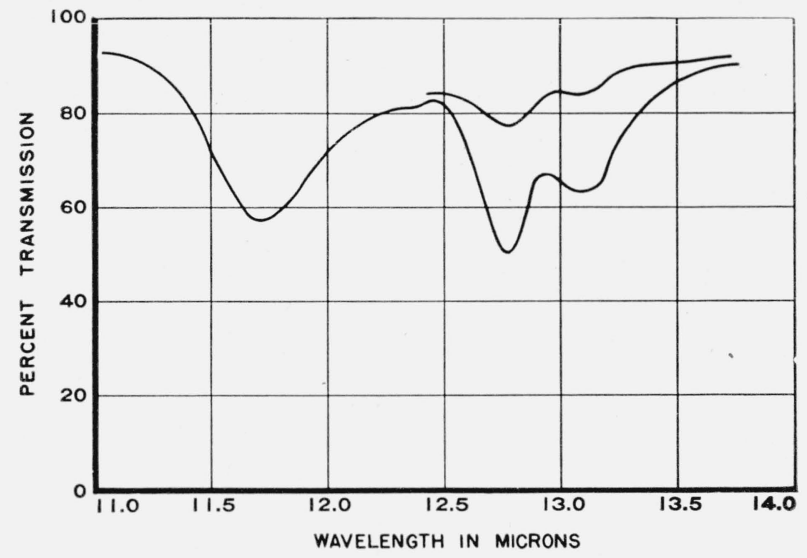

FiguRE 4.-Absorption spectra of two samples of liquid $\mathrm{CS}_{2}$ for a cell, $0.4 \mathrm{~mm}$ in thickness. 
served bands for this region for the two samples. It will be observed that the band at $12.77 \mu$ is much more intense for the Merck sample than for the Baker product. The cell was $0.40 \mathrm{~mm}$ in thickness for each sample. It should be added that the Merck sample had been on a shelf for several years and that the bottle was only partially filled. A deterioration or polymerization in the compound could have taken place. This band has been found by other observers [1], but the varying intensity with different samples has not been previously noted. The other bands do not show such changes, and it appears that this band is due to some other molecule. The possible sources of its origin will be discussed later.

The bands between 3 and $4 \mu$ were measured with a $\mathrm{LiF}$ prism, and in figure 2 the experimental results are given. The band at $3.40 \mu$ has a side band at $3.35 \mu$, and there is a small band at $3.47 \mu$. The two parts of the $3.55-\mu$ band are well resolved, and there is another very weak band at $3.60 \mu$ observed when thick cells were used. The resolution of the LiF prism is much greater than that of the rock-salt prism in this region. In figure 5 is shown the absorption band at $6.5 \mu$ for the vapor of $\mathrm{CS}_{2}$. The presence of a side band is detected on the long-wavelength side. The cell length was $60 \mathrm{~cm}$, and the pressure of the vapor was reduced until it was possible to observe this side band. With the full pressure of the saturated vapor, this band was broad and no structure was observed. When the pressure of the $\mathrm{CS}_{2}$ vapor was reduced to extremely low values, the side band was not observed, and only a double-type band with less absorption at the center appeared.

The band at $11.36 \mu$ due to $\mathrm{CS}_{2}$ vapor is shown in figure 6. The $\mathrm{CS}_{2}$ in liquid form was put in the bottom of the $60-\mathrm{cm}$ cell and allowed to stand for $2 \mathrm{hr}$ before measurement. The separation in wave numbers of the two regions of maximum absorption is about $13.5 \mathrm{~cm}^{-1}$, which checks well with the value found by other observers. Herzberg [7] has questioned the existence of the band at $11.26 \mu$ for the vapor state, but it is readily observed and is of medium intensity. Six bands were observed for the vapor state in the region from 3 to $15 \mu$. They were located at $3.38,3.50,4.28,4.62,6.52$, and $11.36 \mu$. A few isotopic bands, not fully resolved, are not included in this number. All the bands that were observed in the vapor include the

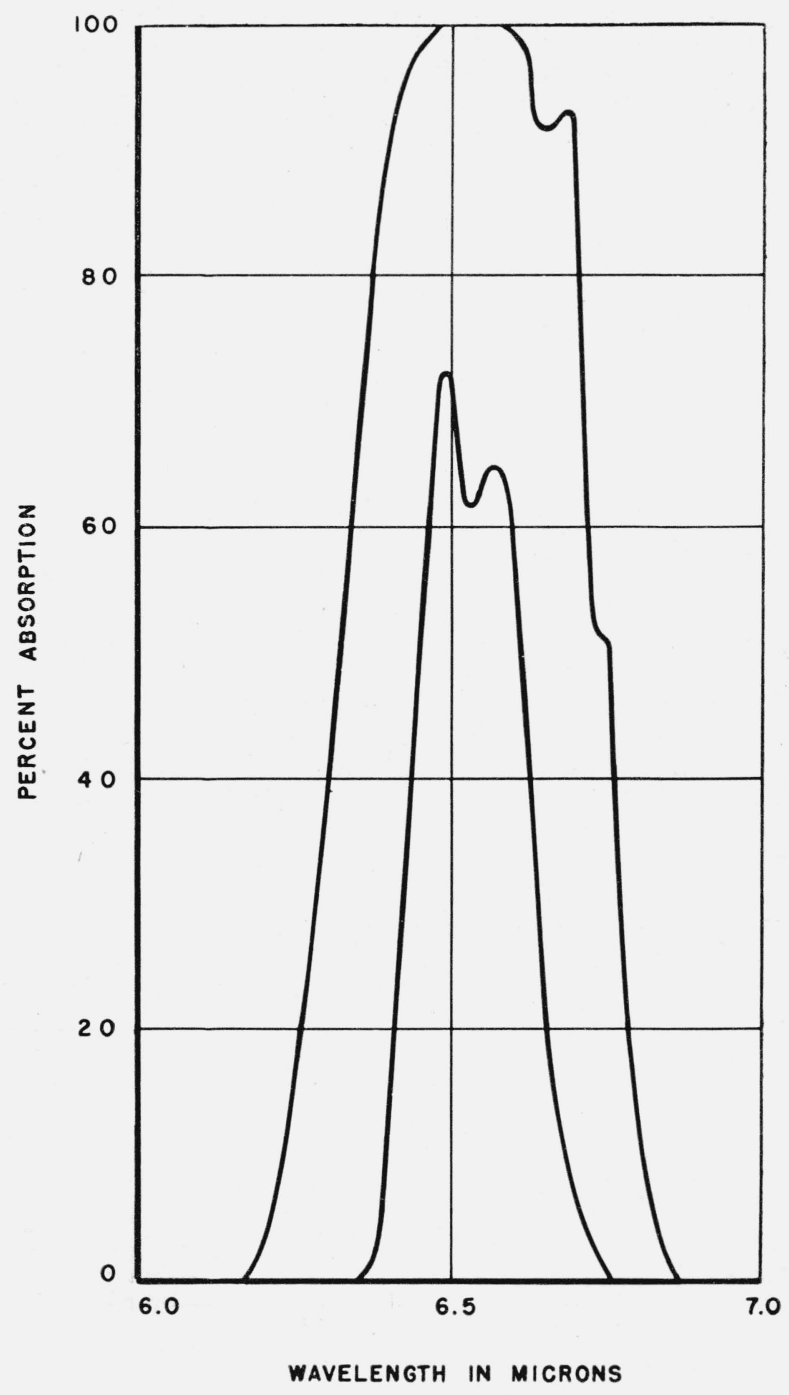

Figure 5.-Absorption of $\mathrm{CS}_{2}$ vapor in the region of $6.5 \mu$.

Upper curve for 60 -cm cell with reduced pressure. Lower curve obtained with a trace of $\mathrm{CS}_{2}$ in the cell.

type of vibration, $\nu_{3}$. As $\nu_{3}$ occurs at slightly shorter wavelengths in the vapor than in the liquid, all these bands are at shorter wavelengths than the corresponding bands for the liquid. The Raman spectrum indicates that the wavelength of the 15.27 band of $\mathrm{CS}_{2}$ is not changed appreciably as the substance is measured in the liquid or vapor state.

The harmonic band, $2 \nu_{3}$, was not observed in the vapor state, which is in agreement with the selection rules. The band, $3 \nu_{3}$, which is allowed by the selection rules was not observed, but this band is of low intensity, and cell lengths greater than those used in this work would be needed for its observa- 


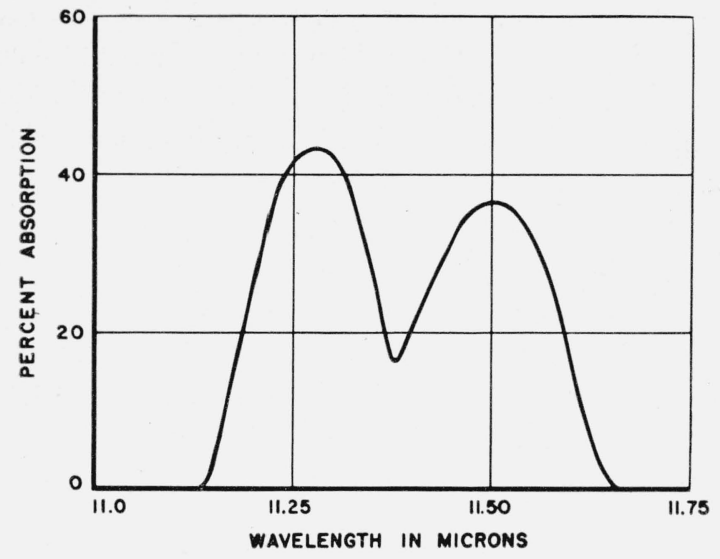

FIGURE 6.-Infrared absorption band of $\mathrm{CS}_{2}$ vapor at $11.36 \mu$. Saturated vapor at $23^{\circ} \mathrm{C}$ with a path length of $60 \mathrm{~cm}$ was used.

tion. The band at $11.36 \mu$, corresponding to a wave number $879 \mathrm{~cm}^{-1}$, is probably due to the combination $\nu_{3}-\nu_{1}$, that is, it is a difference band. By calculation based on previously available data, this band should be located at the wave number $868 \mathrm{~cm}^{-1}$, or $11 \mathrm{~cm}^{-1}$ less than its observed value. This difference is greater than the experimental error, and it appears that either this difference band is out of position or that the previously accepted location of $\nu_{3}$ is not correct. The measurements herein reported permit the explanation and elimination of this discrepancy. This explanation follows.

As $\nu_{1}$ is inactive in the infrared, the wave number of 655 is taken from results obtained by the Raman spectrum. Several observers [7] have measured this band, and their results agree to one or two wave numbers. The band corresponding to $\nu_{3}$ is very intense, and also there exists a side band on the long-wavelength side. Several different amounts of gas were used, and with very small amounts the two branches of the band were observed, as shown in figure 5. The center of the band is located at $1,535 \pm 2 \mathrm{~cm}^{-1}$. This is $12 \mathrm{~cm}^{-1}$ greater than the value accepted on the basis of data to date. The value $1,535 \mathrm{~cm}^{-1}$ also gives better agreement for the band $\nu_{1}+\nu_{3}$. This band is observed at $2,184 \mathrm{~cm}^{-1}$. The calculated value, without the introduction of correction terms, is $2,190 \mathrm{~cm}^{-1}$. The value $1,535 \mathrm{~cm}^{-1}$ for $\nu_{3}$ also removes the difficulty in regard to the position of the difference band $\nu_{3}-\nu_{1}$. The calculated value is $880 \mathrm{~cm}^{-1}$, and the observed value is $879 \mathrm{~cm}^{-1}$. This is within the experimental error.

\section{Discussion of Results}

$\mathrm{CS}_{2}$, in the vapor state, has been measured by Bailey and Cassie [2] and by Dennison and Wright [3]. From the spectrum it was concluded that $\mathrm{CS}_{2}$ was a linear symmetrical molecule, and that the selection rules that Dennison had previously worked out for $\mathrm{CO}_{2}$ should apply to carbon disulfide. Adel and Dennison [8] were able to classify, with excellent agreement, a large number of bands of $\mathrm{CO}_{2}$ that had been observed with long absorbing paths. By the use of a 5-mm cell of $\mathrm{CS}_{2}$ in the liquid state, the percentage absorption should be as large in the bands as for several meters of the vapor. Some changes in the spectra may be produced by the closeness and association of the molecules in the liquid state. Also, the selection rules, which forecast zero intensity for some transitions, may not hold rigidly for the liquid state because of forces between neighboring molecules changing the high degree of symmetry of this type of molecule.

The first difference between the spectra of the liquid and the vapor, which has already been noted, is the change in frequency of band $\nu_{3}$ at $1,535 \mathrm{~cm}^{-1}$. Also, the band $\nu_{1}$. at $655 \mathrm{~cm}^{-1}$, which is very intense in the Raman spectrum, is in the spectrum of the liquid. This band was not observed for the vapor state, and should be inactive in a molecule of this type. The band could arise from a small amount of another substance as thick cells are necessary for its observation. But it is more probably produced by a lack of symmetry introduced by the forces of neighboring molecules. By the use of thick cells, the impurities in the substance become of great importance. One-tenth of 1 percent of some substances in solution in $\mathrm{CS}_{2}$ would give rise to appreciable absorption in certain regions of the spectrum when observed with $5.0-\mathrm{mm}$ cells. In fact, some differences in the spectrum of $\mathrm{CS}_{2}$ were noted with the two different samples. A number of the small bands beyond $7 \mu$ showed slight differences, but such a difference was quite in evidence at $12.77 \mu$. Guilotto and Caldirola [9] used $\mathrm{CS}_{2}$ from Merck \& Co. and obtained this band in the Raman spectrum. By the variation of the intensity of this band in different samples. it is evident that it is produced by another sub:stance as yet unknown. Several of the observed bands of $\mathrm{CS}_{2}$ correspond with the positions of the 
bands of COS [10], and it may be possible that a small amount of this material is present.

The observed and calculated wave numbers of the observed bands and the corresponding terms are given in table 1 . The observed values were not of sufficient accuracy to warrant the calculation of higher-order correction terms. No importance should be attached to the fact that the calculated and observed values agree to less than $5 \mathrm{~cm}^{-1}$ for some terms, as this variation is less than the error in the experimental values for bands of wavelength less than $5 \mu$. The correction terms are small, and this may, in part, account for the rapid decrease in intensity of the harmonics and combination bands.

The harmonic, $2 \nu_{2}$, which arises from the transition, $\left(02^{0} 0 \leftarrow 00^{\circ} 0\right)$, from the ground level, should be inactive and is not observed in the liquid state. However, 2 $\nu_{2}$, which arises from transition, $\left(03^{1} 0 \leftarrow 01^{1} 0\right)$, of one state above the ground level is observed and occurs at $807 \mathrm{~cm}^{-1}$. Both these bands are observed in the Raman spectrum. The band at $807 \mathrm{~cm}^{-1}$ is somewhat displaced from the frequency $794 \mathrm{~cm}^{-1}$ because of the Fermi resonance. Sirkar [11] has found that the Raman spectrum of $\mathrm{CS}_{2}$ in the solid state does not contain the $807-$ $\mathrm{cm}^{-1}$ band. This is in accordance with the interpretation that this band arises from a higher state and not the ground state. At room temperature, a considerable number of the molecules would be out of the lowest level for the band of lowest frequency.

The very intense band at $6.62 \mu$ does not have a first harmonic. There is observed a band at $3.39 \mu$, but this is displaced from the position of the harmonic and the location of this band corresponds closely to the combination $\nu_{1}+\nu_{3}+2 \nu_{2}$. This type of combination gives rise to a band of medium intensity in $\mathrm{CO}_{2}$. The second harmonic is present and is observed at $2.22 \mu$. The combination $\nu_{1}+\nu_{3}$ is observed at $4.62 \mu$, and is a very intense band; a $0.05-\mathrm{mm}$ cell showed 100-percent absorption at the center of this band. A small side band was observed on the long-wavelength side of the combination $\nu_{1}+\nu_{3}$, in both the liquid and the vapor. It is separated from the major band by about $14 \mathrm{~cm}^{-1}$ and is attributed to the isotope $\mathrm{C}^{12} \mathrm{~S}^{32} \mathrm{~S}^{34}$.

Two small bands were observed with wave numbers 1,180 and $1,197 \mathrm{~cm}^{-1}$. With different samples there was a variation in intensity, but the band with wave number $1,197 \mathrm{~cm}^{-1}$ was the more intense in the $\mathrm{CS}_{2}$ from Baker. The $1,180-\mathrm{cm}^{-}$ band is probably due to $3 \nu_{2}$. A weak band was observed at $5.23 \mu$ and checks well with the combination $\nu_{2}+\nu_{3}$. This band should be inactiv by the selection rules and may be due to the isotope $\mathrm{CS}^{32} \mathrm{~S}^{34}$. The combination $\nu_{1}-2 \nu_{2}$, which is observed in the spectrum of $\mathrm{CO}_{2}$ does not appear in the spectrum of $\mathrm{CS}_{2}$ for the cell thickness used

There does not appear to be any evidence for the isomeric form of $\mathrm{CS}_{2}$ with the carbon at one end position. If this molecule were present ir appreciable quantities, there should be observec three active fundamentals, both in the infrared and Raman spectra.

A weak band at $397 \mathrm{~cm}^{-1}$ has been observed in the Raman spectrum by Wood and Collins [12] and by Venkateswaran [13]. For a linear symmetrical molecule this band should not be active in the Raman spectrum. However, the isotope $\mathrm{CS}^{32} \mathrm{~S}^{34}$ would be active, and would produce a band at near the same wave number. A Raman band corresponding to $\nu_{3}$ was observed at $642 \mathrm{~cm}^{-1}$ by Guilotto and Caldirola, and it was attributed to the isotopic molecule.

\section{Isotope Effect}

There are three sulfur atoms with atomic weights of 32,33 , and 34 , and two carbon atoms with atomic weights of 12 and 13 . With these isotopes, 12 molecules could be formed with the carbon atom in the center position. Because of the variation in amount of each isotope, there are only four molecules of $\mathrm{CS}_{2}$ of appreciable amount; these are $\mathrm{C}^{12} \quad \mathrm{~S}_{2}^{32}, \mathrm{C}^{12} \mathrm{~S}^{32} \mathrm{~S}^{33}, \mathrm{C}^{12} \mathrm{~S}^{32} \mathrm{~S}^{34}$, and $\mathrm{C}^{13} \mathrm{~S}^{32}{ }_{2}$. $\quad \mathrm{C}^{12} \mathrm{~S}^{32} \mathrm{~S}^{34}$ makes up about 8 percent of the total quantity, and the other two isotopic molecules are approximately 1 percent in amount. The shift in the bands due to the isotope $\mathrm{S}^{34}$ is small in $\nu_{2}$ and $\nu_{3}$, but amounts to $10 \mathrm{~cm}^{-1}$ in $\nu_{1}$. The $\mathrm{C}^{13}$ does not produce any change in the frequency of $\nu_{1}$, but in $\nu_{3}$ the shift in wave numbers on substitution of $\mathrm{C}^{13}$ is $49 \mathrm{~cm}^{-1}$. The substitution of $\mathrm{S}^{34}$ produces a shift of only $4 \mathrm{~cm}^{-1}$ in $\nu_{3}$. For this reason the band observed on the longwave length side of $\nu_{3}$ in the vapor state is attributed to $\mathrm{C}^{13} \mathrm{~S}^{32}{ }_{2}$.

The equations for the end and central isotope effect for linear triatomic molecules of the $\mathrm{CS}_{2}$ type have been derived by Salant and Rosenthal [14]. Unfortunately, the designation of the three funda- 
mentals by them does not agree with the notation of Dennison [3]. In table 2 are shown the term designations as given by Dennison, and also the calculated wave number of the band for each isotopic molecule. In most cases the change in position due to the presence of $\mathrm{S}^{34}$ is small. It amounts to $1 \mathrm{~cm}^{-1}$ in $\nu_{2}$ and $4 \mathrm{~cm}^{-1}$ in $\nu_{3}$. The bands arising from the less abundant isotopic forms of $\mathrm{CS}_{2}$ are greatly overlapped by the bands due to $\mathrm{C}^{12} \mathrm{~S}_{2}^{32}$, so that many of them are not easily seen. However, in the band $\nu_{3}+2 \nu_{1}$ at $3.55 \mu$, the shift amounts to $24 \mathrm{~cm}^{-1}$ and is just recognized as a side band at low resolution. With the $\mathrm{LiF}$ prism the band is separated from the main branch, and it is found to be about $23 \mathrm{~cm}^{-1}$ less in wave numbers.

TABLE 2.-Isotope effect in carbon disulfide fundamental frequencies for the liquid state

\begin{tabular}{|c|c|c|c|c|c|c|}
\hline \multirow{2}{*}{$\begin{array}{l}\text { Wave- } \\
\text { length }\end{array}$} & \multirow{2}{*}{$\begin{array}{c}\text { Wave } \\
\text { num- } \\
\text { ber } \\
\mathrm{cm}^{-1}\end{array}$} & \multirow{2}{*}{ Term } & \multicolumn{3}{|c|}{ End effect } & \multirow{2}{*}{$\begin{array}{c}\begin{array}{c}\text { Central } \\
\text { effect }\end{array} \\
{ }^{1} 13 S^{32} S^{32}\end{array}$} \\
\hline & & & $C^{12} S^{32} S^{32}$ & $C^{12} S^{32} S^{34}$ & $C^{12} \S^{32} S^{33}$ & \\
\hline \multirow{5}{*}{25.19} & \multirow{5}{*}{397} & \multirow{5}{*}{$\nu_{2}$} & $\Delta^{\nu_{2}}$ & 1 & 1 & 1 \\
\hline & & & $\nu_{2}$ & 418 & 823 & 31 \\
\hline & & & $\Delta^{\nu_{2}}$ & -1 & -0.5 & -13 \\
\hline & & & $\nu_{2}+\Delta \nu_{2}$ & 396 & 3965 & 384 \\
\hline & & & $\underline{\Delta \nu_{1}}$ & -1 & 1 & 0 \\
\hline \multirow{2}{*}{$15.27 \ldots$} & \multirow{2}{*}{655} & \multirow{2}{*}{$\nu_{1}$} & $\nu_{1}$ & 66 & 130 & \\
\hline & & & $\Delta \nu_{1}$ & -10 & -5 & 0 \\
\hline & & & $\nu_{1}+\Delta^{\nu_{1}}$ & 645 & 650 & 655 \\
\hline \multirow{4}{*}{$6.62 \ldots \ldots$} & \multirow{4}{*}{1,510} & \multirow{4}{*}{$\nu_{3}$} & $\underline{\Delta \nu_{3}}$ & 1 & 1 & -1 \\
\hline & & & $\nu_{3}$ & 418 & 823 & 31 \\
\hline & & & $\Delta^{\nu_{3}}$ & -4 & -2 & -49 \\
\hline & & & $\nu_{3}+\Delta^{\nu}$ & 1,506 & 1,508 & 1,461 \\
\hline
\end{tabular}

The band at $12.77 \mu$, which has been observed in both infrared and Raman spectra, was considered by Guilotto and Caldirola [9] to be the isotopic band of $\mathrm{CS}^{32} \mathrm{~S}^{34}$ corresponding to $2 \nu_{2}$. They point out that it is displaced from $794 \mathrm{~cm}^{-1}$ by 11 $\mathrm{cm}^{-1}$, and that the isotope effect as calculated by them should amount to $10 \mathrm{~cm}^{-1}$. However, $2 \nu_{2}$ should have a change of $2 \mathrm{~cm}^{-1}$ for the end isotope effect and $26 \mathrm{~cm}^{-1}$ for the central isotope effect, and it is seen that the isotope effect does not explain the presence of the band at $12.77 \mu$ or wave number $783 \mathrm{~cm}^{-1}$. As has been pointed out before, this band is due to an impurity or to a polymer of $\mathrm{CS}_{2}$. Several very weak bands were observed in the region 7 to $15 \mu$. These bands may be due to the isotopic molecules or to impurities. These bands were of the order of magnitude in intensity of the band at $2.88 \mu$. This weak band was included because it corresponded to the combination term, $\nu_{3}+3 \nu_{1}$, which also was observed for cells of considerable length in $\mathrm{CO}_{2}$.

\section{Conclusion}

The spectrum of liquid $\mathrm{CS}_{2}$ has been classified in terms and combinations analogous to those that have been found to exist for $\mathrm{CO}_{2}$. All the intense bands except one, fall into the forecast terms. Some weak bands are also classified. The spectrum supports the conclusion that the molecular configuration of $\mathrm{CS}_{2}$ is linear and symmetrical. The selection rules are followed very well, but not in all cases. As forecast by theory, $2 \nu_{2}$ at $794 \mathrm{~cm}^{-1}$ and $2 \nu_{3}$ at $3,014 \mathrm{~cm}^{-1}$ are not observed, but $3 \nu_{2}$ and $3 \nu_{3}$ are present as weak bands.

Except for the region of 4.6 and $6.6 \mu$, thin cells of $\mathrm{CS}_{2}$ are fairly transparent from the visible region to $24 \mu$. For this reason it is useful as a solvent in infrared measurements.

\section{References}

[1] W. W. Coblentz, Pub. Carnegie Inst. of Washington, No. 35 (1935).

[2] C. R. Bailey and A. B. D. Cassie, Proc. Toy. Soc. (London) 132, 236 (1931).

[3] D. M. Dennison and N. Wright, Phys. Rev. 38, 2077 (1931).

[4] J. A. Sanderson, Phys. Rev. 50, 209 (1935).

[5] L. N. Lieberman, Phys. Rev. 60, 496 (1941).

[6] E. K. Plyler, R. Stair, C. J. Humphreys, J. Research NBS 38, 211 (1947) RP1769.

[7] G. Herzberg, Infrared and Raman spectra of polyatomic molecules (D. Van Nostrand Co., New York, N. Y., 1945).

[8] A. Adel and D. M. Dennison, Phys. Rev. 43, 716 (1933).

[9] L. Guilotto and P. Caldirola, Z. Physik Chem. [B] 49, 34 (1941).

[10] P. F. Bartunek and E. F. Barker, Phys. Rev. 48, 516 (1935).

[11] S. C. Sirkar, Ind. J. Phys. 10, 189 (1936).

[12] R. W. Wood and G. Collins, Phys. Rev. 42, 386 (1932).

[13] S. Venkateswaran, Phil. Mag. [7] 14, 258 (1932).

[14] E. O. Salant and J. E. Rosenthal, Phys. Rev. 42, 812 (1932).

Washington, February 11, 1947 